\title{
Risk Factor Analysis for Central Lymph Node Metastasis in Papillary Thyroid Microcarcinoma
}

\section{Wenfei Liu* \\ Shoufei Wang* \\ Xiaotian Xia}

Department of Thyroid, Parathyroid, Breast and Hernia Surgery, Shanghai Jiao Tong University Affiliated Sixth People's Hospital, Shanghai, People's Republic of China

*These authors contributed equally to this work

Video Abstract

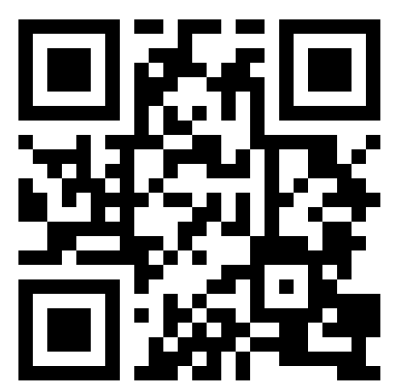

Point your SmartPhone at the code above. If you have a QR code reader the video abstract will appear. Or use: https://youtu.be/KdDUrSX6A7Q

Correspondence: Xiaotian Xia $\mathrm{Tel}+86$ 18930172917

Email 189301729I7@I63.com
Purpose: Although the prognosis of papillary thyroid microcarcinoma (PTMC) is excellent, cervical lymph node metastasis (CLNM) is commonly observed in PTMC. This study aimed to investigate the incidence and risk factors for CLNM in PTMC.

Patients and Methods: Altogether, 687 patients with PTMC who initially underwent unilateral thyroidectomy with unilateral central lymph node dissection or bilateral thyroidectomy with bilateral central lymph node dissection between January 2014 and June 2018 at our hospital were included. The patients were divided into two groups: PTMC with CLNM and PTMC with no CLNM. The clinicopathologic characteristics and ultrasound features were compared between the groups. Univariate and multivariate logistic regression analyses were used to identify the risk factors for CLNM.

Results: CLNM was observed in 121/687 (17.6\%) patients with PTMC. PTMC patients aged $<55$ years exhibited a greater incidence of CLNM (87.6\% vs $12.4 \%)$ than those aged $\geq 55$ years. PTMC patients with CLNM were more likely to have capsular extension $(24.0 \%$ vs $15.4 \%$ ) and extension to the adjacent structures (9.9\% vs $4.2 \%)$. Patients with microcalcification on ultrasound images were more likely to have CLNM $(66.1 \%$ vs $47.9 \%)$. Multivariate logistic regression analysis revealed that microcalcification (odds ratio [OR]: 2.066, 95\% confidence interval [CI]: $1.361-3.135, P<0.001$ ), age $<55$ years (OR: $2.341,95 \%$ CI: $1.309-4.187, P=0.004$ ), capsular invasion (OR: $1.772,95 \% \mathrm{CI}: 1.082-2.879, P=0.023$ ), and invasion of the adjacent tissues (OR: 2.872, 95\% CI: 1.355-4.187, $P=0.004$ ) were significant risk factors for CLNM.

Conclusion: Microcalcification, age $<55$ years, capsular invasion, and invasion of the adjacent tissues were significant risk factors for CLNM in PTMC.

Keywords: risk factors, papillary thyroid microcarcinoma, microcalcification, age, invasion

\section{Introduction}

Papillary thyroid microcarcinoma (PTMC) is defined as a malignant thyroid tumor sized $\leq 1 \mathrm{~cm} .{ }^{1}$ PTMC is a subtype of papillary thyroid cancer (PTC) and accounts for approximately $30-50 \%$ of the PTCs. ${ }^{2}$ In recent years, the prevalence of thyroid microcarcinoma has increased rapidly, mainly due to the detection of thyroid nodules using advanced ultrasound (US). ${ }^{3,4}$ It is well known that most of the PTMCs are indolent with excellent prognosis and the long-term survival rate is over $99 \%{ }^{5}$ However, central lymph node metastasis (CLNM) is common and may be observed in $21.4-60 \%$ of the PTMCs. ${ }^{2,6-10}$ CLNM might be the main risk factor for tumor recurrence. ${ }^{11}$ Although prophylactic central lymph node dissection can reduce tumor recurrence rates and reoperation-related complications, it can result in surgical complications such as permanent hypocalcemia and recurrent laryngeal nerve injury. ${ }^{12,13}$ Therefore, the decision 
to perform prophylactic central lymph node dissection for PTMC is still controversial. Although several previous studies have assessed the risk factors for CLNM in PTMC, these factors remain unclear to date. It is necessary to analyze the clinicopathological characteristics and US characteristics of PTMC patients to determine the independent risk factors for CLNM in thyroid microcarcinoma and to formulate a relatively reasonable surgical plan.

\section{Materials and Methods}

This present study was approved by the Ethics Committee of Shanghai Sixth People's Hospital and all patients provided informed consent to participate in this study.

The clinicopathological characteristics of PTMC patients included age, sex, tumor size, presence of chronic thyroiditis, degree of tumor invasion, surgical methods, single or multifocal tumor, and dissected lymph nodes. According to the eighth edition of the Oncology Manual, patients were classified as $\geq 55$ years of age and $<55$ years of age. For unifocal tumors, the tumor size was calculated as the largest diameter of the tumor. For multifocal tumors, the tumor size was calculated as the largest diameter of the largest mass. According to the postoperative paraffin section pathological report, tumor invasion was classified as invasion within the thyroid capsule, invasion into the capsule, and tumor extension to the adjacent tissues outside the capsule. Tumor within the thyroid capsule refers to a mass within the gland and not extending to the capsule. Tumor invading the capsule refers to a mass that is close to the surface of the thyroid and invades the capsule. Tumor extending to the adjacent tissues outside the capsule refers to a mass that breaks through the thyroid capsule and invades tissues such as fat and muscles outside the gland. Chronic thyroiditis has been studied as a risk factor or a protective factor for CLNM. $^{14,15}$ For patients with unilateral PTC, unilateral thyroidectomy was performed with unilateral central lymph node dissection. For patients with bilateral PTC or PTC arising from the isthmus, bilateral thyroidectomy and bilateral central lymph node dissection were performed. US features considered in this study included tumor shape, tumor boundary, microcalcification, and suspicion of CLNM. The shape of the mass was classified as regular or irregular and the boundary of the mass was classified as clear or unclear. Microcalcifications were defined as punctate hyperechoic lesions within the tumor with a size $\leq 2 \mathrm{~mm}$. Neck US examinations were performed at our hospital 1 week before the surgery. Patients with a tumor size $>1 \mathrm{~cm}$ were excluded.
The chi-squared test was used to analyze the differences in the clinical variables between patients with CLNM and those without CLNM. Univariate and multivariate logistic regression analyses were used to verify the risk factors for thyroid microcarcinoma. Variables with $P$-values below 0.05 in the univariate logistic regression analysis were included in the multivariate logistic regression analysis. The programming software $\mathrm{R}$ (version 4.0.5, https://www.r-project.org) (the $\mathrm{R}$ foundation, Vienna, Austria) was used for statistical analyses.

\section{Results \\ Clinical Characteristics}

Altogether, 687 patients with PTMC were included in the study. CLNM was observed in 121 (17.6\%) patients with PTMC, while 566 (82.4\%) PTMC patients did not exhibit CLNM. The study included $164(23.9 \%)$ men and 523 (76.1\%) women. Altogether, 528 (76.9\%) patients aged $<55$ years and $159(23.1 \%)$ patients aged $\geq 55$ years were included in our investigation. Total thyroidectomy with bilateral central lymph node dissection was performed in 215 (31.3\%) PTMC patients, while $472(68.7 \%)$ underwent lobectomy and isthmusectomy with ipsilateral bilateral central lymph node dissection.

\section{Ultrasound Features}

Altogether, 276 (40.2\%) and 411 (59.8\%) patients had tumors with irregular and regular shapes, respectively. Tumors with unclear margins were observed in 385 (56.0\%) patients, while 302 patients $(44.0 \%)$ had tumors with clear margins. Microcalcifications within the tumor were observed in 351 (51.1\%) patients, while 336 (48.9\%) patients had tumors without microcalcifications. CLNM was suspected on US imaging in 41 patients $(6.0 \%)$.

\section{Pathological Features}

Tumor size was $\geq 5 \mathrm{~mm}$ in 503 (73.2\%) patients, while 184 (26.8\%) patients had tumor size $<5 \mathrm{~mm}$. Altogether, 84 (12.2\%) PTMC patients had multifocal tumors. Tumors were confined to the capsule in $535(77.9 \%)$ patients, extension to the capsule was observed in $116(16.9 \%)$ patients, and extension to the adjacent structures was observed in $36(5.2 \%)$ patients. The detailed information is presented in Table 1.

\section{Statistical Analysis}

Analysis with chi-squared test showed significant differences in patient age, tumor extension, and the presence or 
Table I Detailed Information of All PTMC Patients

\begin{tabular}{|c|c|}
\hline & Overall \\
\hline $\mathbf{n}$ & 687 \\
\hline \multicolumn{2}{|l|}{ CLNM, n (\%) } \\
\hline Yes & $121(17.6)$ \\
\hline No & $566(82.4)$ \\
\hline \multicolumn{2}{|l|}{ Sex, n (\%) } \\
\hline Male & $164(23.9)$ \\
\hline Female & $523(76.1)$ \\
\hline \multicolumn{2}{|l|}{ Irregular shape, n (\%) } \\
\hline Yes & $276(40.2)$ \\
\hline No & $4 I I(59.8)$ \\
\hline \multicolumn{2}{|l|}{ Unclear margin, n (\%) } \\
\hline Yes & $385(56.0)$ \\
\hline No & $302(44.0)$ \\
\hline \multicolumn{2}{|l|}{ Microcalcification, n (\%) } \\
\hline Yes & $35 I(5 I . I)$ \\
\hline No & $336(48.9)$ \\
\hline \multicolumn{2}{|l|}{ Suspected CLNM, n (\%) } \\
\hline Present & $4 I(6.0)$ \\
\hline Absent & $646(94.0)$ \\
\hline \multicolumn{2}{|l|}{ Age, n (\%) } \\
\hline$<55$ years & $528(76.9)$ \\
\hline$\geq 55$ years & $159(23.1)$ \\
\hline \multicolumn{2}{|l|}{ Multifocal, n (\%) } \\
\hline Present & $84(12.2)$ \\
\hline Absent & $603(87.8)$ \\
\hline \multicolumn{2}{|l|}{ Size, n (\%) } \\
\hline$\geq 5 \mathrm{~mm}$ & $503(73.2)$ \\
\hline$<5 \mathrm{~mm}$ & I 84 (26.8) \\
\hline \multicolumn{2}{|l|}{ CLT, n (\%) } \\
\hline Present & $109(15.9)$ \\
\hline Absent & $578(84.1)$ \\
\hline \multicolumn{2}{|l|}{ Tumor extension, n (\%) } \\
\hline Confined into the capsule & 535 (77.9) \\
\hline Extension to the capsule & $116(16.9)$ \\
\hline Extension to adjacent structures & $36(5.2)$ \\
\hline \multicolumn{2}{|l|}{ Surgical resection, n (\%) } \\
\hline Total thyroidectomy with bilateral CLND & $215(31.3)$ \\
\hline Lobectomy plus isthmusectomy with ipsilateral CLND & $472(68.7)$ \\
\hline No. of the harvested lymph nodes (mean (SD)) & $3.91(1.32)$ \\
\hline
\end{tabular}

Abbreviations: CLNM, central lymph node metastasis; CLT, chronic lymphatic thyroiditis; CLND, central lymph node dissection; PTMC, papillary thyroid microcarcinoma.

absence of microcalcification $(P<0.05)$ between the groups. Sex, tumor boundary, and other variables did not show significant differences.
As shown in Table 2, PTMC patients with CLNM were more likely to have an extension to the capsule $(24.0 \%$ vs $15.4 \%)$ or extension to the adjacent structures $(9.9 \%$ vs $4.2 \%$ ) compared to those without CLNM. Patients with microcalcification on US imaging were more likely to

Table 2 Comparison of Information Between PTMC Patients with NCLNM and PTMC with CLNM

\begin{tabular}{|c|c|c|c|}
\hline Factors & NCLNM & CLNM & $P$ value \\
\hline $\mathrm{n}$ & $566(82.4)$ & $|2|(17.6)$ & \\
\hline \multicolumn{4}{|l|}{ Sex, n (\%) } \\
\hline Male & $130(23.0)$ & $34(28.1)$ & 0.278 \\
\hline Female & $436(77.0)$ & 87 (71.9) & \\
\hline \multicolumn{4}{|l|}{ Irregular shape, n (\%) } \\
\hline Yes & $220(38.9)$ & $56(46.3)$ & 0.159 \\
\hline No & $346(6 \mathrm{I} .1)$ & $65(53.7)$ & \\
\hline \multicolumn{4}{|l|}{ Unclear margin, n (\%) } \\
\hline Yes & $312(55.1)$ & $73(60.3)$ & 0.344 \\
\hline No & $254(44.9)$ & $48(39.7)$ & \\
\hline \multicolumn{4}{|l|}{ Microcalcification, n (\%) } \\
\hline Yes & $27 \mid(47.9)$ & $80(66.1)$ & $<0.001$ \\
\hline No & $295(52.1)$ & $4 I(33.9)$ & \\
\hline \multicolumn{4}{|l|}{ Suspected CLNM, n (\%) } \\
\hline Present & 31 (5.5) & $10(8.3)$ & 0.335 \\
\hline Absent & $535(94.5)$ & III (9I.7) & \\
\hline \multicolumn{4}{|l|}{ Age, n (\%) } \\
\hline$<55$ years & $422(74.6)$ & $106(87.6)$ & 0.003 \\
\hline$\geq 55$ years & $144(25.4)$ & $15(12.4)$ & \\
\hline \multicolumn{4}{|l|}{ Multifocal, n (\%) } \\
\hline Present & $70(12.4)$ & $14(11.6)$ & 0.928 \\
\hline Absent & $496(87.6)$ & $107(88.4)$ & \\
\hline \multicolumn{4}{|l|}{ CLT, n (\%) } \\
\hline Present & 97 (17.1) & $12(9.9)$ & 0.066 \\
\hline Absent & $469(82.9)$ & $109(90.1)$ & \\
\hline \multicolumn{4}{|l|}{ Tumor extension, n (\%) } \\
\hline Confined into the capsule & $455(80.4)$ & $80(66.1)$ & 0.001 \\
\hline Extension to the capsule & $87(15.4)$ & $29(24.0)$ & \\
\hline Extension to adjacent structures & $24(4.2)$ & $12(9.9)$ & \\
\hline \multicolumn{4}{|l|}{ Size, n (\%) } \\
\hline$\geq 5 \mathrm{~mm}$ & $410(72.4)$ & $93(76.9)$ & 0.377 \\
\hline$<5 \mathrm{~mm}$ & $156(27.6)$ & $28(23.1)$ & \\
\hline \multicolumn{4}{|l|}{ Surgical resection, $\mathbf{n}(\%)$} \\
\hline $\begin{array}{l}\text { Total thyroidectomy with } \\
\text { bilateral CLND }\end{array}$ & $|8|(32.0)$ & $34(28.1)$ & 0.467 \\
\hline $\begin{array}{l}\text { Lobectomy plus isthmusectomy } \\
\text { with ipsilateral CLND }\end{array}$ & $385(68.0)$ & 87 (71.9) & \\
\hline
\end{tabular}

Abbreviations: CLNM, central lymph node metastasis; NCLNM, non central lymph node metastasis; CLT, chronic lymphatic thyroiditis, PTMC, papillary thyroid microcarcinoma. 
have CLNM (66.1\% vs 47.9\%) compared to those without microcalcification. Univariate analysis showed that microcalcification, age, and tumor invasion were significantly correlated with CLNM $(P<0.05)$ as shown in Table 3.

Table 3 Univariate Analysis of Variables Related to Central Lymph Node Metastasis (CLMN)

\begin{tabular}{|c|c|c|c|}
\hline Characteristics & OR & $95 \% \mathrm{Cl}$ & $P$ value \\
\hline \multicolumn{4}{|l|}{ Sex } \\
\hline Male & 1.311 & $0.842-2.04$ & 0.2304 \\
\hline Female & Reference & & \\
\hline \multicolumn{4}{|l|}{ Age } \\
\hline$<55$ years & 2.411 & $1.36-4.276$ & 0.0026 \\
\hline$\geq 55$ years & Reference & & \\
\hline \multicolumn{4}{|l|}{ Size } \\
\hline$\geq 5 \mathrm{~mm}$ & 1.264 & $0.797-2.004$ & 0.3196 \\
\hline$<5 \mathrm{~mm}$ & Reference & & \\
\hline \multicolumn{4}{|l|}{ Irregular shape } \\
\hline Yes & 1.355 & $0.913-2.012$ & 0.132 \\
\hline No & Reference & & \\
\hline \multicolumn{4}{|l|}{ Unclear margin } \\
\hline Yes & 1.238 & $0.83-1.847$ & 0.2954 \\
\hline No & Reference & & \\
\hline \multicolumn{4}{|l|}{ Microcalcification } \\
\hline Yes & 2.124 & $1.408-3.204$ & 0.0003 \\
\hline No & Reference & & \\
\hline \multicolumn{4}{|l|}{ Suspected CLNM } \\
\hline Present & 1.555 & $0.74 I-3.264$ & 0.2434 \\
\hline Absent & Reference & & \\
\hline \multicolumn{4}{|l|}{ Multifocal } \\
\hline Present & 0.837 & $0.487-1.437$ & 0.5176 \\
\hline Absent & Reference & & \\
\hline \multicolumn{4}{|l|}{ CLT } \\
\hline Present & 0.532 & $0.282-1.004$ & 0.0516 \\
\hline Absent & Reference & & \\
\hline \multicolumn{4}{|l|}{ Tumor extension } \\
\hline Confined into the capsule & Reference & & \\
\hline Extension to the capsule & 1.896 & I.17-3.072 & 0.0094 \\
\hline $\begin{array}{l}\text { Extension to adjacent } \\
\text { structures }\end{array}$ & 2.844 & $1.367-5.916$ & 0.0052 \\
\hline \multicolumn{4}{|l|}{ Surgical resection } \\
\hline $\begin{array}{l}\text { Total thyroidectomy with } \\
\text { bilateral CLND }\end{array}$ & 0.831 & $0.539-1.283$ & 0.4039 \\
\hline $\begin{array}{l}\text { Lobectomy plus } \\
\text { isthmusectomy with } \\
\text { ipsilateral CLND }\end{array}$ & Reference & & \\
\hline
\end{tabular}

Abbreviations: CLNM, central lymph node metastasis; CLT, chronic lymphatic thyroiditis; CLND, central lymph node dissection; PTMC, papillary thyroid microcarcinoma; OR, odds ratio; $\mathrm{Cl}$, confidence Interval.
Table 4 Multivariate Analysis of Variables Related to Central Lymph Node Metastasis (CLMN)

\begin{tabular}{|l|r|l|r|}
\hline & \multicolumn{1}{|l|}{ OR } & 95\% Cl & P value \\
\hline $\begin{array}{l}\text { Microcalcification } \\
\text { Yes }\end{array}$ & 2.066 & $1.361-3.135$ & $<0.001$ \\
No & Reference & & \\
\hline $\begin{array}{l}\text { Tumor extension } \\
\text { Confined into the capsule } \\
\text { Extension to the capsule } \\
\text { Extension to adjacent } \\
\text { structures }\end{array}$ & $\begin{array}{r}\text { Reference } \\
1.772\end{array}$ & $1.083-2.897$ & 0.023 \\
\hline $\begin{array}{l}\text { Age } \\
<55 \text { years }\end{array}$ & $1.355-6.089$ & 0.006 \\
$\geq 55$ years & 2.341 & $1.309-4.187$ & 0.004 \\
\hline
\end{tabular}

Abbreviations: OR, odds ratio; $\mathrm{Cl}$, confidence Interval.

Multivariate analysis revealed that microcalcification (odds ratio [OR]: 2.066, 95\% confidence interval [CI]: 1.361-3.135, $P<0.001$ ), age $<55$ years (OR: $2.341,95 \%$ CI: $1.309-4.187, P=0.004)$, extension to the capsule (OR: 1.772, 95\% CI: $1.083-2.897, P=0.023)$ and extension to the adjacent structures (OR: 2.287, 95\% CI: 1.355-6.089, $P=0.006$ ) were significantly associated with CLNM. The detailed information is presented in Table 4.

\section{Discussion}

PTMC is described as a malignant thyroid tumor with a maximum diameter $\leq 1 \mathrm{~cm}$. In recent years, the prevalence of PTMC has increased rapidly due to advancements in detection technologies such as the US. ${ }^{16,17}$ It is well known that PTMC is an indolent cancer with an excellent prognosis. The 10-year disease-free survival rate is over 96\%. ${ }^{5}$ However, CLNM is commonly observed in PTMC. According to a previous investigation, approximately $35.5 \%$ of the PTMCs have CLNM. ${ }^{9}$ The central area is the first station of CLNM. Moreover, metastasis to the central area is the most common form of CLNM. ${ }^{8-10,18}$ However, the decision regarding the implementation of preventive cervical lymph node dissection is still controversial. Several researchers believed that performance of routine central neck dissection could attain a less recurrence, better outcomes, reduced postoperative thyroglobulin levels and a lower morbidity rate related to initial operation. $^{19,20}$ Nevertheless, others thought that more aggressive process could increases the threat of surgical complication such as permanent hypocalcemia, hypoparathyroidism and recurrent laryngeal nerve paralysis. ${ }^{21,22}$ Therefore, the present study retrospectively analyzed the 
clinicopathological and US characteristics of 678 patients with PTMC to analyze the risk factors associated with CLNM in a single-institution. We observed that the rate of CLNM in thyroid microcarcinoma was $17.6 \%$. In a previous study, the incidence of CLNM in PTMC ranged from $24.1 \%$ to $64.1 \%{ }^{2,6-10}$ The high incidence of CLNM indicates that it is relatively reasonable to perform prophylactic central lymph node dissection in PTMC patients.

The results of the present study suggested that patients aged $<55$ years were more likely to develop CLNM than patients aged $\geq 55$ years, indicating that younger patients should be monitored more carefully, and clinicians should consider prophylactic central lymph dissection in younger patients. Several previous studies have shown that age is closely related to CLNM in patients with PTMC. Liu et al demonstrated that age $<45$ years was significantly associated with CLNM. ${ }^{23}$ The age cut-off of 45 years has been adopted in the commonly used staging system for differentiated thyroid cancer for many years. However, Nixon et al identified that a cut-off of 55 years would enhance the precision of the staging system and would suitably avoid overstaging and overtreatment of low-risk patients. ${ }^{24}$ Therefore, the age cut-off was changed from 45 years to 55 years in the eighth edition of the American Joint Committee on Cancer (AJCC)/The Union for International Cancer Control staging system. Currently, it is not clear whether a cut-off age of 45 years or 55 years would be suitable for predicting CLNM in PTMC patients. However, our findings confirmed that patients under 55 years of age had a higher incidence of CLNM than those over 55 years of age.

We observed that microcalcification inside the tumor on US imaging was also a dependent risk factor for CLNM in PTMC patients. Johannessen and Sobrinho-Simoes demonstrated the pathogenesis of calcification in the thyroid for the first time. A probable reason for microcalcification is that the rapid proliferation of cancer cells may lead to proliferation and mixed necrosis of cancer tissues, leading to calcium deposition and calcification. Necrotic calcification caused by tumor thrombus is another probable reason. ${ }^{25}$ Thus, microcalcification is due to the proliferation of blood vessels and fibrous tissue, which reflects the rapid growth of the mass to a certain extent. Oh et al confirmed that PTMC patients with presence of microcalcification on US imaging exhibited a higher rate of lymph node metastasis, which was consistent with our results. ${ }^{26}$ Therefore, clinicians should pay careful attention to the possibility of CLNM in PTMC patients with microcalcification on US imaging.

We observed that tumor extension was significantly associated with CLNM. When compared with tumors confined to the capsule, tumors extending to the capsule or the adjacent tissues exhibited a higher probability of CLNM. Gui et al demonstrated that extrathyroidal extension was associated with CLNM in PTMC. ${ }^{27}$ Moreover, extrathyroidal extension was emphasized as an unfavorable prognostic factor in the eighth edition of the AJCC staging manual. Therefore, PTMC patients with tumor extension to the capsule or the adjacent tissues including the strap muscles, recurrent laryngeal nerves, larynx, trachea, esophagus, veins, and carotid artery were more likely to develop CLNM.

Our study has several limitations. The existence of data bias and deviation due to the retrospective study design was unavoidable. Central lymph node dissection was performed in all patients with PTMC, which might have resulted in medical overtreatment. The relevant data from the present investigation was limited to a single institution. Data from multiple institutions are needed to study the risk factors for CLNM in PTMC.

\section{Conclusion}

We observed that microcalcification on US imaging, age $<55$ years, and extension to the capsule or the adjacent tissues were significantly associated with CLNM. These findings could be beneficial for the clinicians in confirming CLNM in PTMC patients.

\section{Abbreviations}

PTMC, papillary thyroid microcarcinoma; PTC, papillary thyroid carcinoma; US, ultrasound; CLNM, central lymph node metastasis; AJCC, American Joint Committee on Cancer; OR, odds ratio; CI, confidence interval.

\section{Code Availability}

The code used or analyzed during the current study are available from the corresponding author on reasonable request.

\section{Data Sharing Statement}

The datasets used or analyzed during the current study are available from the corresponding author on reasonable request. 


\section{Ethics Statement}

This study was conducted with the approval of the Ethics Committee of Shanghai Jiao Tong University Affiliated Sixth People's Hospital and in accordance with the declaration of Helsinki. Written informed consent was obtained from all participants.

\section{Acknowledgments}

The authors would like to thank all the reviewers who participated in the review.

We would like to thank Editage (www.editage.com) for English language editing.

\section{Funding}

This research did not receive any specific grant from funding agencies in the public, commercial, or not-forprofit sectors.

\section{Disclosure}

The authors report no conflicts of interest.

\section{References}

1. Walgama E, Sacks WL, Ho AS. Papillary thyroid microcarcinoma: optimal management versus overtreatment. Curr Opin Oncol. 2020;32(1):1-6. doi:10.1097/CCO.0000000000000595

2. Liu Z, Wang L, Yi P, Wang CY, Huang T. Risk factors for central lymph node metastasis of patients with papillary thyroid microcarcinoma: a meta-analysis. Int J Clin Exp Pathol. 2014;7(3):932-937.

3. Haber RS. Role of ultrasonography in the diagnosis and management of thyroid cancer. Endocr Pract. 2000;6(5):396-400. doi:10.4158/ ep.6.5.396

4. Li F, Zhang J, Wang Y, Liu L. Clinical value of elasticity imaging and contrast-enhanced ultrasound in the diagnosis of papillary thyroid microcarcinoma. Oncol Lett. 2015;10(3):1371-1377. doi:10.3892/ ol.2015.3387

5. Hay ID, Hutchinson ME, Gonzalez-Losada T, et al. Papillary thyroid microcarcinoma: a study of 900 cases observed in a 60-year period. Surgery. 2008;144(6):980-988. doi:10.1016/j.surg.2008.08.035

6. Chow SM, Law SCK, Chan JKC, Au SK, Yau S, Lau WH. Papillary microcarcinoma of the thyroid - prognostic significance of lymph node metastasis and multifocality. Cancer. 2003;98(1):31-40. doi:10.1002/cncr.11442

7. Yin X, Liu C, Guo Y, et al. Influence of tumor extent on central lymph node metastasis in solitary papillary thyroid microcarcinomas: a retrospective study of 1092 patients. World J Surg Oncol. 2017;15 (1). doi:10.1186/s12957-017-1202-8

8. Wada N, Duh Q-Y, Sugino K, et al. Lymph node metastasis from 259 papillary thyroid microcarcinomas. Ann Surg. 2003;237(3):399-407. doi:10.1097/01.sla.0000055273.58908.19

9. Zheng X, Peng C, Gao M, et al. Risk factors for cervical lymph node metastasis in papillary thyroid microcarcinoma: a study of 1587 patients. Cancer Biol Med. 2019;16(1):121-130. doi:10.20892/j. issn.2095-3941.2018.0125

10. Zhao Q, Ming J, Liu C, et al. Multifocality and total tumor diameter predict central neck lymph node metastases in papillary thyroid microcarcinoma. Ann Surg Oncol. 2013;20(3):746-752. doi:10. 1245/s10434-012-2654-2
11. Siddiqui S, White MG, Antic T, et al. Clinical and pathologic predictors of lymph node metastasis and recurrence in papillary thyroid microcarcinoma. Thyroid. 2016;26(6):807-815. doi:10.1089/thy.20 15.0429

12. Xue S, Wang P, Liu J, Li R, Zhang L, Chen G. Prophylactic central lymph node dissection in cN0 patients with papillary thyroid carcinoma: a retrospective study in China. Asian J Surg. 2016;39 (3):131-136. doi:10.1016/j.asjsur.2015.03.015

13. So YK, Seo MY, Son YI. Prophylactic central lymph node dissection for clinically node-negative papillary thyroid microcarcinoma: influence on serum thyroglobulin level, recurrence rate, and postoperative complications. Surgery. 2012;151(2):192-198. doi:10.1016/j.surg. 2011.02.004

14. Babli S, Payne RJ, Mitmaker E, Rivera J. Effects of chronic lymphocytic thyroiditis on the clinicopathological features of papillary thyroid cancer. Eur Thyroid J. 2018;7(2):95-101. doi:10.1159/ 000486367

15. Aydoğan Bİ, Mutlu ABB, Yüksel S, et al. The association of histologically proven chronic lymphocytic thyroiditis with clinicopathological features, lymph node metastasis, and recurrence rates of differentiated thyroid cancer. Endocr Pathol. 2021;32(2):280-287. doi:10.1007/s12022-020-09653-y

16. Dean DS, Gharib H. Epidemiology of thyroid nodules. Best Pract Res Clin Endocrinol Metab. 2008;22(6):901-911. doi:10.1016/j. beem.2008.09.019

17. Guth S, Theune U, Aberle J, Galach A, Bamberger CM. Very high prevalence of thyroid nodules detected by high frequency $\left(13^{\circ} \mathrm{MHz}\right)$ ultrasound examination. Eur J Clin Invest. 2009;39(8):699-706. doi:10.1111/j.1365-2362.2009.02162.x

18. Lim YC, Choi EC, Yoon YH, Kim EH, Koo BS. Central lymph node metastases in unilateral papillary thyroid microcarcinoma. Br J Surg. 2009;96(3):253-257. doi:10.1002/bjs.6484

19. Calò PG, Pisano G, Medas F, et al. Total thyroidectomy without prophylactic central neck dissection in clinically node-negative papillary thyroid cancer: is it an adequate treatment? World J Surg Oncol. 2014;12(1):152. doi:10.1186/1477-7819-12-152

20. Shan CX, Zhang W, Jiang DZ, Zheng XM, Liu S, Qiu M. Routine central neck dissection in differentiated thyroid carcinoma: a systematic review and meta-analysis. Laryngoscope. 2012;122 (4):797-804. doi:10.1002/lary.22162

21. Docimo G, Tolone S, Conzo G, et al. A gelatin-thrombin matrix topical hemostatic agent (Floseal) in combination with harmonic scalpel is effective in patients undergoing total thyroidectomy: a prospective, multicenter, single-blind, randomized controlled trial. Surg Innov. 2016;23(1):23-29. doi:10.1177/1553350615596638

22. Conzo G, Calò PG, Gambardella C, et al. Controversies in the surgical management of thyroid follicular neoplasms. Retrospective analysis of 721 patients. Int $J$ Surg. 2014;12(S1):S29-S34. doi:10.1016/j.ijsu.2014.05.013

23. Liu LS, Liang J, Li JH, et al. The incidence and risk factors for central lymph node metastasis in $\mathrm{cN} 0$ papillary thyroid microcarcinoma: a meta-analysis. Eur Arch Otorhinolaryngol. 2017;274 (3):1327-1338. doi:10.1007/s00405-016-4302-0

24. Nixon IJ, Kuk D, Wreesmann V, et al. Defining a valid age cutoff in staging of well-differentiated thyroid cancer. Ann Surg Oncol. 2016;23(2):410-415. doi:10.1245/s10434-015-4762-2

25. Johannessen JV, Sobrinho-Simoes M. The origin and significance of thyroid psammoma bodies. Lab Investig. 1980;43(3):287-296.

26. Oh EM, Chung YS, Song WJ, Lee YD. The pattern and significance of the calcifications of papillary thyroid microcarcinoma presented in preoperative neck ultrasonography. Ann Surg Treat Res. 2014;86 (3):115-121. doi:10.4174/astr.2014.86.3.115

27. Gui CY, Qiu SL, Peng ZH, Wang M. Clinical and pathologic predictors of central lymph node metastasis in papillary thyroid microcarcinoma: a retrospective cohort study. J Endocrinol Invest. 2018;41 (4):403-409. doi:10.1007/s40618-017-0759-y 


\section{Publish your work in this journal}

The International Journal of General Medicine is an international, peer-reviewed open-access journal that focuses on general and internal medicine, pathogenesis, epidemiology, diagnosis, monitoring and treatment protocols. The journal is characterized by the rapid reporting of reviews, original research and clinical studies across all disease areas. The manuscript management system is completely online and includes a very quick and fair peer-review system, which is all easy to use. Visit http://www.dovepress.com/ testimonials.php to read real quotes from published authors.

Submit your manuscript here: https://www.dovepress.com/international-journal-of-general-medicine-journal 